\title{
Effects of Ultraviolet Irradiation on the Migratory Ability of Primordial Germ Cells (PGCs) in the Domestic Chicken
}

\author{
Takeo Minematsu, Yukio Kanai and Atsushi Tajima ${ }^{1}$ \\ Institute of Agriculture and Forestry, University of Tsukuba, \\ 1-1-1 Ten-noh Dai, Tsukuba, Ibaraki 305-8572, Japan
}

The effect of ultraviolet (UV) irradiation on the ability of primordial germ cells (PGCs) to migrate toward the gonadal ridge was investigated in the domestic chicken.

When PGCs were irradiated with UV $\left(254 \mathrm{~nm}, 0.9 \pm 0.1 \mu \mathrm{W} / \mathrm{cm}^{2}\right)$ the extent of nuclear damage, as determined by the comet assay, was positively correlated with the duration of UV irradiation in the range from 0 to 60 seconds. However, no further increase in nuclear damage was detected when the duration of UV irradiation was extended from 60 to 120 seconds.

To evaluate the migratory ability of PGCs after UV irradiation, 15 fluorescentlabeled PGCs were transferred into the vascular system of 2-day-old embryos and the fluorescent-labeled PGCs present in the gonads of recipient embryos were counted 5 days later. When the duration of UV irradiation was less than 60 seconds, the number of fluorescent-labeled PGCs found in the gonads of the recipient embryos exceeded the number of transferred PGCs.

In conclusion, the ability of PGCs to migrate toward the developing gonad is retained after exposure to UV irradiation that causes apparent damage to the nucleus.

Key words : UV irradiation, PGCs, Migratory ability, embryo, chicken

\section{Introduction}

Since the discovery of the migratory nature of primordial germ cells (PGCs) (Meyer, 1964), the mechanism of PGC migration has been an important and stimulating research topic in developmental biology.

In all known vertebrates, including avian species, gametes are derived from PGCs, which originate in the extra-embryonic region (Fujimoto et al. 1989 ; Buehr, 1997 ; Ginsburg, 1997). Kuwana (1993) reviewed the migration of avian PGCs toward the gonadal ridge. In avian species, extra-embryonic PGCs first circulate within the vascular system before migrating to the gonadal ridge (Fujimoto et al. 1976). It has been suggested that PGCs are attracted by unidentified chemical substance(s) released from the gonadal ridge (Kuwana and Rogulska, 1999). In addition, fibronectin and tenascin- $\mathrm{C}$ are present in the extracellular matrix through which the PGCs migrate to reach the genital ridges (Anstrom and Tucker, 1996). However, the exact mechanism

\footnotetext{
Received : November 28, 2003, Accepted : January 19, 2004

${ }^{1}$ Correspondence to : Atsushi Tajima, Institute of Agriculture and Forestry, University of Tsukuba, Tsukuba, Ibaraki 305-8572, Japan.

Tel : +81-298-53-6688 Fax : +81-298-53-6205 E-mail : tajima@sakura.cc.tsukuba.ac.jp
} 
of PGC migration remains to be resolved.

To elucidate the mechanism of PGC migration, it was thought that a partial impairment of cellular function, such as that induced by exposure to PGCs to ultraviolet (UV) irradiation, would offer an alternative means of studying the mode of PGC migration.

Short-wave UV light induces intrastrand DNA cross-links between adjacent pyrimidines, forming cyclobutane pyrimidine dimers (CPD) and pyrimidine-(6-4)pyrimidone photoproducts (6-4PP) (Setlow and Carrier, 1966 ; Mori et al. 1991 ; Moné et al. 2001). The presence of CPDs and 6-4PPs inhibits DNA replication (Rupp and Howard-Flanders, 1968 ; Radman, 1971) and transcription (Herrlich et al. 1994 ; Van Hoffen et al. 1999 ; Moné et al. 2001). Ijiri (1976) revealed that UV irradiation of fertilized eggs resulted in the elimination of germ cell formation in Xenopus laevis. Reynaud (1977) showed that UV irradiation of the chick blastoderm significantly decreased the number of germ cells in the gonads of 5-day-old embryos.

Recent progress in the development of techniques for producing germline chimeras by PGC transfer in avian species (Nakamura et al. 1991 ; Yasuda et al. 1992 ; Tajima et al. 1993 ; Naito et al. 1994a, 1994b ; Ono et al. 1996 ; Tajima et al. 1998) has provided a way to assess the effects of manipulating PGCs on their migratory ability.

This study investigated the effect of direct UV irradiation of PGCs on their ability to migrate toward the gonadal ridge in the domestic chicken.

\section{Materials and Methods}

\section{Experiment 1 : Cellular damage with UV irradiation of PGCs Sample preparation}

Fertilized White Leghorn eggs (Agricultural and Forestry Research Center, University of Tsukuba, Japan) were incubated at $37.8^{\circ} \mathrm{C}$ for 50 to 65 hours. Embryonic blood was collected from the dorsal aorta of the embryos at stages 13-15 of development (Hamburger and Hamilton, 1951) using fine glass needles prepared by pulling 50 $\mu l$ glass pipettes (Drummond Sci. CN) with a micro-pipette puller (PA-81-8811, Narishige, Japan). The collected blood was dispersed in $100 \mu l$ of Minimum Essential Medium (MEM) containing 10\% fetal bovine serum (FBS).

The PGCs were isolated from embryonic blood using a modification of the Ficoll density gradient centrifuge method reported by Chang et al. (1992), and washed using the filtration method of Tajima et al. (2003). Ficoll (Sigma Chem. MO) was dissolved at $16 \%(\mathrm{w} / \mathrm{v})$ in MEM containing 10\% FBS. Blood samples were overlaid on $1 \mathrm{ml}$ of $16 \%$ Ficoll solution in $1.5-\mathrm{ml}$ centrifuge tubes. After centrifugation at $800 \times \mathrm{g}$ for 30 minutes, $200 \mu \mathrm{l}$ of the PGC-rich supernatant was recovered and placed on 5- $\mu \mathrm{m}$ mesh nylon filters (Small Parts, FL). The nylon filters were dampened with MEM containing $10 \%$ FBS just before use. The PGCs on the nylon filters were washed three times with $50 \mu \mathrm{l}$ of MEM containing 10\% FBS. The nylon filters were then placed in $100 \mu \mathrm{l}$ of MEM containing $10 \%$ FBS in $1.5-\mathrm{m} l$ centrifuge tubes and agitated using a Vortex mixer. To recover the cells from the nylon filters, the filters were fixed at the top of the centrifuge tubes, adjacent to the cap, and centrifuged at $800 \times \mathrm{g}$ for 30 minutes.

After centrifugation, the samples were divided into two fractions of equal volume 
: one fraction was subjected to UV irradiation, whereas the remaining fraction was used as an untreated control. A total of 24 samples were prepared and each sample was randomly assigned to one of the four periods of UV irradiation $(10,30,60$, or 120 seconds).

A dual monochromator microfluorometer (JASCO, Japan) was used for UV irradiation. The samples were placed on Heavy Teflon-coated Slides (HTCS ; Erie Sci. $\mathrm{NH}$ ) and incubated at room temperature for $5 \mathrm{~min}$ to allow the cells to settle. The samples were exposed to $254 \mathrm{~nm} \mathrm{UV} \mathrm{irradiation} \mathrm{at} 0.9 \pm 0.1 \mu \mathrm{W} / \mathrm{cm}^{2}$, for 0 to 120 seconds.

After incubation for 4 hours at $37^{\circ} \mathrm{C}$, the DNA damage and PGC viability were evaluated using single-cell gel electrophoresis (comet assay) and a fluorescent doublestaining technique, respectively.

\section{DNA damage assay}

Approximately 100 PGCs were recovered from each sample using fine glass needles and dispersed in $10 \mu \mathrm{l}$ of $0.5 \%$ low melting-point (LMP) agarose gel. The PGC-agarose suspensions were placed on frosted glass slides, which were pre-coated with a thin layer of $0.65 \%$ normal melting point agarose. The samples were immediately covered with 18 $\times 18 \mathrm{~mm}$ cover glasses and placed at $4^{\circ} \mathrm{C}$ for 15 minutes. The cover glasses were then gently removed, a second layer of LMP agarose was added, the coverslip replaced, and the slide returned to $4^{\circ} \mathrm{C}$ for an additional 15 minutes.

After removing the cover glasses, the slides were immersed in a lysing solution $(2.5$ $\mathrm{M} \mathrm{NaCl}, 100 \mathrm{mM} \mathrm{Na}{ }_{2}$ EDTA, $10 \mathrm{mM}$ Tris, $3 \mathrm{M} \mathrm{NaOH}, 1 \%$ sodium lauroyl sarcosine, $1 \%$ Triton $\mathrm{X}-100,10 \% \mathrm{DMSO}$ ) at $4{ }^{\circ} \mathrm{C}$ for $1 \mathrm{~h}$ to lyse the PGCs and permit DNA unfolding. The slides were then washed gently with distilled water, and placed in a horizontal gel electrophoresis unit filled with fresh electrophoretic buffer $(300 \mathrm{mM}$ $\mathrm{NaOH}$, and $1 \mathrm{mM} \mathrm{Na} \mathrm{m}_{2}$ EDTA) for $20 \mathrm{~min}$ to allow the DNA to unwind. Electrophoresis was conducted for $5 \mathrm{~min}$ at $300 \mathrm{~mA}, 25-27 \mathrm{~V}$ using a Power Pac 1000 (Bio-Rad, CA).

After electrophoresis, the agarose on the glass slides was gently washed with distilled water and soaked at room temperature in three changes of $0.4 \mathrm{M}$ Tris buffer ( $\mathrm{pH}$ 7.5) for 15 minutes each, to remove alkali and detergents. A few drops of SYBR Green I (Takara, Japan), diluted $1: 10,000$ in TBE buffer ( $89 \mathrm{mM}$ Tris, $89 \mathrm{mM}$ boric acid, $2 \mathrm{mM} \mathrm{Na} \mathrm{NaDT}_{2}$ ), were placed on each agarose gel, and the gels were covered with cover glasses. The slides were placed at room temperature in the dark for 30 minutes. Stained nuclei and DNA were visualized using an inverted fluorescent microscope (IMT-2, Olympus, Japan) with a 490-nm excitation filter. The length of each "comet" (Fig. 1) of 50 randomly selected PGCs was measured using a micrometer.

The experiment was repeated 6 times and t-test was used to analyze the statistical difference in comet length between control and UV irradiated sample within each period of UV irradiation. A net increase in the comet length was calculated and subjected to a statistical analysis using one-way ANOVA followed by Duncan's multiple range test.

\section{Cell viability assay}




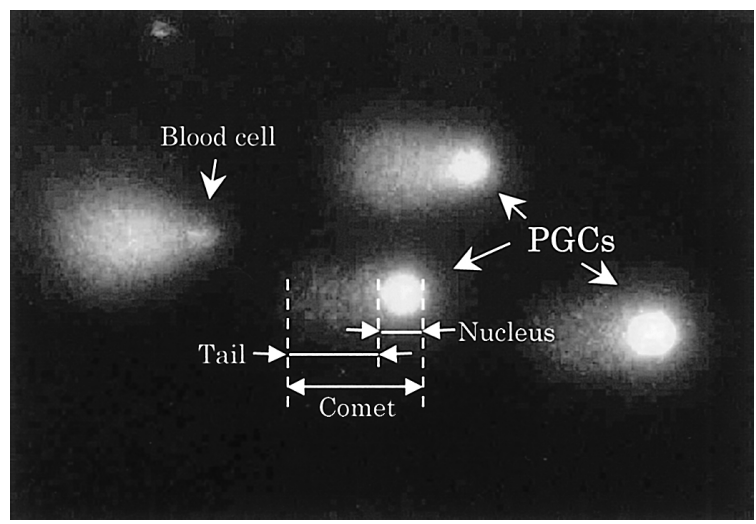

Fig. 1. DNA damage assay (Comet assay).

Ultraviolet-irradiated PGCs were embedded in a low melting point agarose gel. After lysis, the sample was electrophoresed, and stained with SYBR Green I. The effect of UV irradiation was estimated by measuring the lengths of the observed "comets".

The viability of PGCs was assessed by staining with propidium iodide (PI) and fluorescein diacetate (FDA). Only the plasma membranes of dead cells permit PI to penetrate and emit red fluorescence on binding to DNA (Johnson, 1995). By contrast, FDA emits green fluorescence only in viable cells that possess the esterase activity necessary to convert the non-fluorescent precursor into fluorescein (Kasten, 1981).

Propidium iodide (Wako, Japan) was diluted with Dulbecco's PBS at a concentration of $1 \mathrm{mg} / \mathrm{ml}$. Fluorescein diacetate (Wako, Japan) was diluted with acetone at a concentration of $10 \mathrm{mg} / \mathrm{ml}$. These stock solutions were stored at $4^{\circ} \mathrm{C}$ and $-20^{\circ} \mathrm{C}$, respectively.

Each PGC sample was combined with $10 \mu \mathrm{l}$ each of the PI and FDA stock solutions and incubated at $37.8^{\circ} \mathrm{C}$ for 5 minutes. Stained PGCs were examined by fluorescent microscopy using 490-nm and 546-nm excitation filters for FDA and PI, respectively (Fig. 2), and the dead cells (PI-positive and FDA-negative) were counted. The experiment was repeated 6 times. The viability of randomly selected 50 PGCs was measured for each treatment and t-test was used to analyze the statistical difference between control and UV irradiated samples within each period of UV irradiation.

\section{Experiment 2 : Evaluating the migratory ability of UV-irradiated PGCs}

Approximately $5 \mu \mathrm{l}$ of blood collected from a Rhode Island Red embryo was dispersed in $50 \mu \mathrm{l}$ of MEM supplemented with $10 \%$ FBS. The sample was placed on an HTCS and incubated at room temperature for $5 \mathrm{~min}$. Twenty-five samples were prepared and an equal number of samples assigned to each of the five periods of UV irradiation $(0,10,30,60$, and 120 seconds). Ultraviolet irradiation was performed using the same method as in Experiment 1.

After UV irradiation, 15 PGCs were picked up using a fine glass needle after labeling with PKH-26 (Zynaxis, PA). The PGCs were injected into recipient embryos 

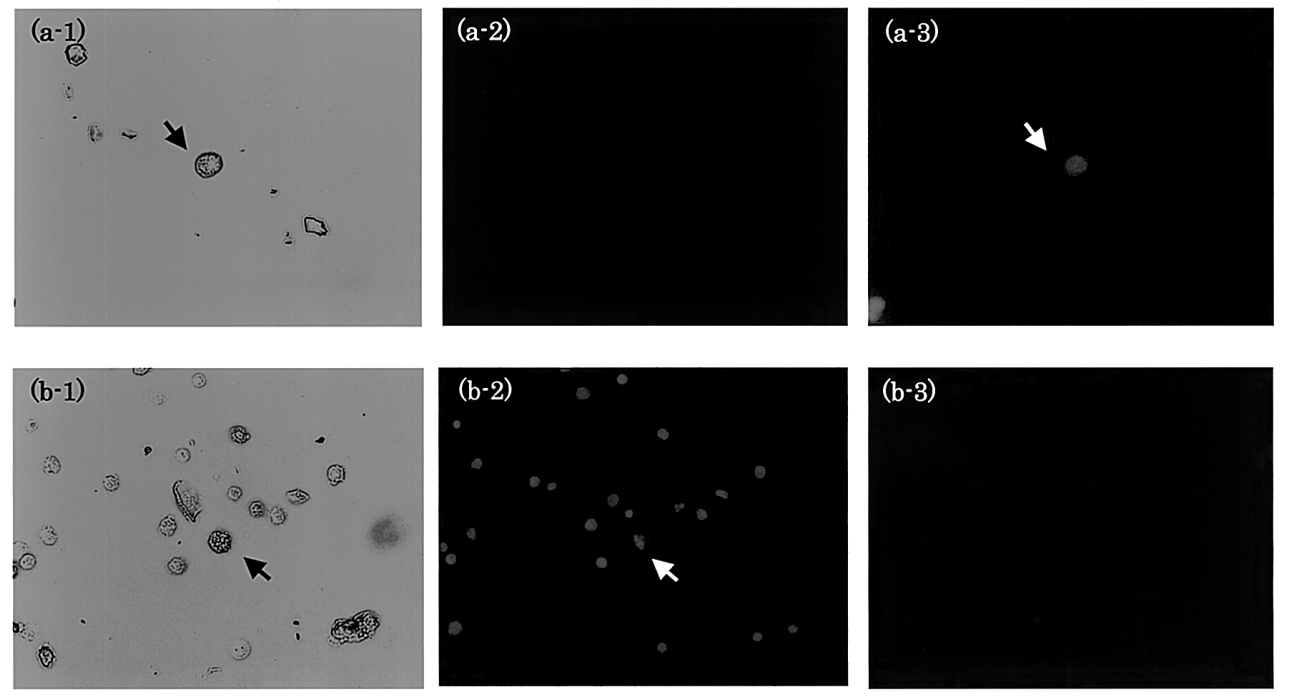

Fig. 2. Cell viability assay.

(a-1) and (b-1): Light photomicrographs of PGCs after UV irradiation.

(a-2) and (b-2) : Fluorescent photomicrographs of UV-irradiated PGCs after staining with PI, with a 546-nm excitation filter.

(a-3) and (b-3) : Fluorescent microscopic picture of UV-irradiated PGCs after staining with FDA, with a 490-nm excitation filter.

The PGCs in (a-1), (a-2), and (a-3) are PI-negative and FDApositive, whereas the PGCs in (b-1), (b-2), and (b-3) are PIpositive and FDA-negative.

using the method of Tajima et al. (1998). Briefly, fluorescent-labeled PGCs were injected into the dorsal aorta of a 2-day-old RIR recipient embryo at stages 15-16 of development, via a small window cut in the shell. Approximately $5 \mu l$ of blood had been removed 2 or 3 hours before the injection of PGCs. After injection, the window was sealed with plastic tape and the egg was incubated at $37.8^{\circ} \mathrm{C}$.

Five days after injection, the recipient embryos were dissected under a dissection microscope (SZH, Olympus, Japan) and both the right and left gonadal ridges were collected. The collected gonadal ridges were immersed in $50 \mu l$ of $0.1 \%$ trypsin in Dulbecco's PBS $(-)$ on an HTCS, minced under the dissection microscope, and incubated at $37.8^{\circ} \mathrm{C}$ for 5 minutes. After mixing, $50 \mu l$ of bovine adult serum was added to terminate the enzyme reaction. The total number of PGCs labeled with PKH-26 recovered from each gonadal ridge was counted under an inverted fluorescent microscope, using a 546-nm excitation filter. The experiment was repeated 5 times. A statistical analysis was performed by one-way ANOVA followed by Duncan's multiple range test. 


\section{Results}

\section{Experiment 1 : Cellular damage with UV irradiation of PGCs}

The DNA damage induced by UV irradiation of PGCs was investigated using single-cell gel electrophoresis (comet assay) (Fig. 1). In this assay, electrophoresis of individual lysed cells in agarose permits damaged DNA to migrate away from the nucleus, forming the "tail" of a "comet", consisting of a nuclear body and a migrated DNA tail. In this study, the length of a comet was defined as the total length of the comet from the leading edge of the nucleus to the tip of the tail. The intensity of DNA damage corresponds to the length of a comet (Sastre et al. 2001).

As shown in Table 1, UV irradiation significantly increased the length of a comet as compared with non-UV-irradiated controls when the period of UV irradiation exceeded 10 seconds. A significant dose-dependent net increase in comet length was observed in all of the irradiated samples when the period of irradiation was less than 60 seconds $(p<0.05)$. However, no further increase in comet length was observed when the UV irradiation time was increased from 60 to 120 seconds.

The viability of PGCs was investigated by fluorescent double staining with PI and FDA. No significant differences in the percentage of PI-positive/FDA-negative PGCs were observed after UV irradiation for 10 to 120 seconds. Although there was no significant difference, a slight increase in the percentage of PI-positive/FDA-negative PGCs was observed when the period of UV irradiation was 120 seconds (Table 1).

\section{Experiment 2 : Migratory ability of irradiated PGCs}

Figure 3 shows the numbers of PKH-labeled PGCs recovered from gonadal ridges

Table 1. The effects of UV irradiation on PGCs (Mean \pm SE)

\begin{tabular}{|c|c|c|c|c|c|}
\hline \multirow{2}{*}{$\begin{array}{l}\text { Period of } \\
\text { UV } \\
\text { irradiation }\end{array}$} & \multirow{2}{*}{ Treatment } & \multicolumn{2}{|c|}{ Comet length ${ }^{1}(\mu \mathrm{m})$} & \multicolumn{2}{|c|}{ Percentage of dead PGCs } \\
\hline & & Average & $\begin{array}{l}\text { Net increase } \\
\text { (UV-Control) }\end{array}$ & PI-positive & FDA-negative \\
\hline \multirow{2}{*}{$10 \mathrm{sec}$} & Control & $40.8 \pm 0.6$ & \multirow{2}{*}{$4.5 \pm 0.5^{\mathrm{D}}$} & $0.8 \pm 0.8$ & $4.0 \pm 1.1$ \\
\hline & UV & $45.3 \pm 0.7^{*}$ & & $1.6 \pm 0.8$ & $3.2 \pm 1.5$ \\
\hline \multirow{2}{*}{$30 \mathrm{sec}$} & Control & $42.2 \pm 0.2$ & \multirow{2}{*}{$8.6 \pm 0.6^{\mathrm{C}}$} & $1.6 \pm 0.8$ & $3.6 \pm 1.2$ \\
\hline & UV & $50.8 \pm 0.2^{*}$ & & $2.4 \pm 1.2$ & $6.8 \pm 2.1$ \\
\hline \multirow{2}{*}{$60 \mathrm{sec}$} & Control & $39.1 \pm 0.1$ & \multirow{2}{*}{$16.8 \pm 1.9^{\mathrm{A}}$} & $2.4 \pm 0.8$ & $2.8 \pm 1.2$ \\
\hline & UV & $55.9 \pm 0.2^{*}$ & & $1.6 \pm 0.8$ & $4.0 \pm 0.9$ \\
\hline \multirow{2}{*}{$120 \mathrm{sec}$} & Control & $41.8 \pm 0.1$ & \multirow{2}{*}{$13.2 \pm 0.7^{\mathrm{B}}$} & $1.6 \pm 0.8$ & $4.8 \pm 0.8$ \\
\hline & UV & $55.0 \pm 0.1^{*}$ & & $6.0 \pm 4.6$ & $12.4 \pm 4.8$ \\
\hline
\end{tabular}

${ }^{1}$ Comet length: The total length of the comet, including the diameter of the nuclear body and the length of the tail.

* Comet length of UV treatment was significantly longer than that of the control $(p<0.05)$.

A-D Values with different letters in the same column are significantly different $(p<$ 0.05). 


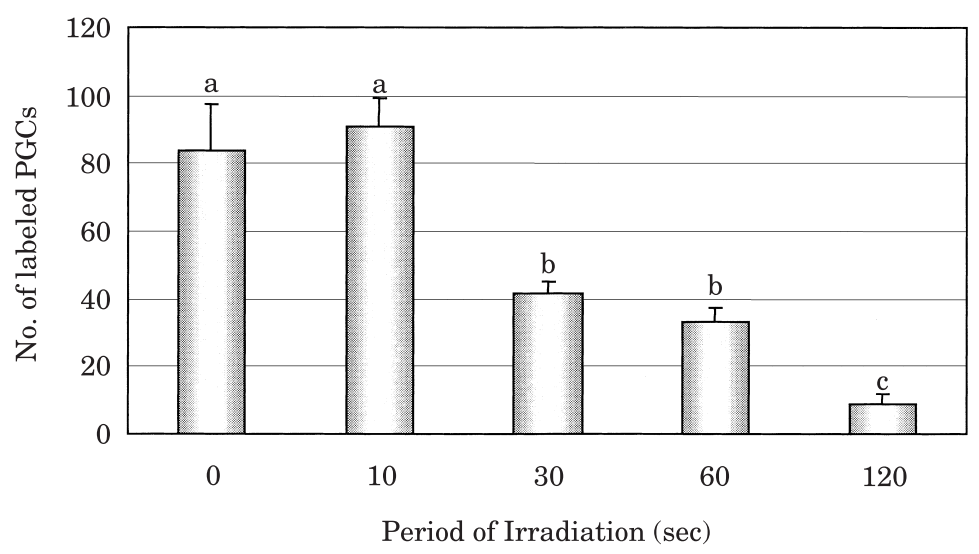

Fig. 3. Migratory ability of PGCs after UV irradiation.

Fifteen UV-irradiated PKH-labeled PGCs were injected into the dorsal aorta of embryos at stages $15-16$ of development. The injected embryos were incubated for 5 days. The total number of PKH-labeled PGCs in both the right and left gonadal ridges was counted after digestion with $0.1 \%$ trypsin.

${ }^{\text {acc }}$ Values marked with different letters are significantly different $(p<0.05)$.

5 days after transfer. There were 83.6 $\pm 13.66,90.6 \pm 8.66,41.4 \pm 3.59,33.0 \pm 4.64$, and 9.2 \pm 2.60 PKH-labeled PGCs with 0, 10, 30, 60, and 120 seconds of UV irradiation, respectively.

A significant decrease in the number of PKH-labeled PGCs in the recipient gonad was observed when the period of UV irradiation increased from 10 to 30 seconds and from 60 to 120 seconds $(p<0.05)$. By contrast, no significant difference in the number of PKH-positive germ cells was observed between 0 and 10 seconds or between 30 and 60 seconds of UV irradiation.

\section{Discussion}

Low level DNA damage to a single cell caused by UV irradiation (Sastre et al. 2001), X-ray irradiation, or $\mathrm{H}_{2} \mathrm{O}_{2}$ treatment (Singh et al. 1988) can be quantified using the comet assay because DNA lesions, such as CPDs and 6-4 PPs produced in the cell by UV irradiation, are removed by a mechanism generally known as nucleotide excision repair (NER) (Van Hoffen et al. 1995).

Preliminary experiments showed that 4 hours of incubation after UV irradiation are required before a measurable "tail" of a "comet" can be observed. It is thought that the DNA fragments seen as the "tail" are produced by the NER reaction during the incubation period.

Comet tails were observed in all of the untreated control cells. Although we did not determine the exact reason for the presence of tails in the control cells, we speculate that the major component was RNA, which is abundant in the cells. In addition, the comet tails in the control cells could be due partly to the naturally occurring NER 
activity of PGCs. Therefore, the difference in the comet length between the controls and UV-irradiated cells was thought to be the result of NER activity in the PGCs after UV irradiation.

When PGCs were irradiated with UV $\left(254 \mathrm{~nm}, 0.9 \pm 0.1 \mu \mathrm{W} / \mathrm{cm}^{2}\right)$ for $0-60$ seconds, the intensity of DNA damage, as determined by the NER activity of PGCs, was positively correlated with the period of UV irradiation. However, no further increase in the comet length was detected when the period of UV irradiation was extended from 60 to 120 seconds. Our results indicate that the NER activity of PGCs plateaued at 60 seconds of UV irradiation with our experimental conditions.

The effect of UV irradiation on the viability of PGCs was estimated by double staining with PI and FDA. No significant increase in the proportion of dead cells was observed when the period of the UV irradiation was less than 60 seconds. Although the difference was not statistically significant, a slight increase in the proportion of dead PGCs was observed when the period of UV irradiation was increased to 120 seconds (Table 1). In addition, in the PGC transfer experiment, the number of PKH-positive cells recovered from the recipient gonads was less than the number of transferred cells only when the period of UV irradiation was 120 seconds. These results indicate that the nucleus of PGCs was irreversibly damaged by 120 seconds of UV irradiation, which is likely to result in cell death.

A significant decrease in the total number of PKH-positive cells recovered from the gonads of recipient embryos was observed when the period of UV irradiation was increased from 10 to 30 seconds. Conversely, the total number of PKH-positive cells in the gonads of the recipient embryos always exceeded the number of injected PGCs, for all periods of irradiation less than 60 seconds.

It has been reported that the UV irradiation inhibits DNA replication (Rupp and Howard-Flanders, 1968 ; Radman, 1971) as well as gene transcription (Herrlich et al. 1994 ; Van Hoffen et al. 1999 ; Moné et al. 2001). Therefore, we hypothesized that UV irradiation of PGCs for less than 60 seconds inhibits the proliferation of PGCs rather than their migration. In order to examine the proliferating ability of PGCs after UV exposure, histological as well as in vitro culture studies need to be carried out in the future.

In a recent study of polar plasm in Drosophila, factors necessary for germ cell migration, such as Nanos protein (Kobayashi et al. 1996) and Polar granule component RNA (Nakamura et al. 1996), were reported to exist within the polar plasm. Tsunekawa et al. (2000) reported the presence of a germ-plasm-like cytoplasmic structure in chick germ cells, and proposed that the chicken germline is determined by maternally inherited factors in the germ plasm. Cellular factors related to PGC migration may also be present in the germ plasm in avian species. If UV irradiation inhibits gene transcription in PGCs, all of the cellular factors required by the PGCs for successful migration toward the gonadal ridge should be present in the circulating PGCs.

In conclusion, the ability of irradiated chicken PGCs to migrate toward the gonadal ridge was retained even after apparent damage to the nuclear DNA. In order 
to clarify the mechanism of migration, future research should be directed toward searching for and analyzing cellular factor(s) that play key role(s) in PGC migration.

\section{Acknowledgment}

The authors are thankful for the technical support provided by the staff of the Animal Science Division of the Agricultural and Forestry Research Center, University of Tsukuba.

\section{References}

Anstrom KK and Tucker RP. Tenascin-C lines the migratory pathways of avian primordial germ cells and hematopoietic progenitor cells. Developmental Dynamics, 206 : 437-446. 1996.

Buehr M. The primordial germ cells of mammals : some current perspectives. Experimental Cell Research, 232 : 194-207. 1997.

Chang IK, Tajima A, Yasuda Y, Chikamune T and Ohno T. Simple method for isolation of primordial germ cells from chick embryos. Cell Biology International Reports, 16 : 853-857. 1992.

Fujimoto T, Ukeshima A and Kiyofuji R. The origin, migration and morphology of the primordial germ cells in the chick embryo. The Anatomical Record, 185 : 139-154. 1976.

Fujimoto T, Ukeshima A, Miyayama Y, Kuwana T, Yoshinaga K and Nakamura M. The primordial germ cells in amniotes : their migration in vitro and behaviors in vitro. Progress in Clinical and Biological Research, 296 : 13-21. 1989.

Ginsburg M. Primordial germ cell development in avians. Poultry Science, $76: 91-95.1997$.

Hamburger V and Hamilton HL. A series of normal stages in the development of the chick embryo. Journal of Morphology, 88 : 49-92. 1951.

Herrlich P, Sachsenmaier C, Radler-Pohi A, Gebel S, Blattner C and Rahmsdorf HJ. The mammalian UV response : mechanism of DNA damage induced gene expression. Advances in Enzyme Regulation, 34 : 381-395. 1994.

Ijiri KI. UV effect on germ cell determinant and a proposed scheme for germ cell formation process in embryos of Xenopus laevis. Journal of Radiation Research, 17 : 247-261. 1976.

Johnson JE. Methods for studying cell death and viability in primary neuronal cultures. Methods in Cell Biology, 46 : 243-276. 1995.

Kasten FH. Methods for fluorescence microscopy. In : Staining Procedures, Fourth edition (Clark G ed) pp. 39-103. The Biological Stain Commission, MD. 1981.

Kobayashi S, Yamada M, Asaoka M and Kitamura T. Essential role of the posterior morphogen nanos for germline development in Drosophila. Nature, 380 : 708-711. 1996.

Kuwana T. Migration of avian primordial germ cells toward the gonadal anlage. Development, Growth and Differentiation, 35 : 237-243. 1993.

Kuwana T and Rogulska T. Migratory mechanisms of chick primordial germ cells toward gonadal anlage. Cellular and Molecular Biology, 45 : 725-736. 1999.

Meyer DB. Migration of primordial germ cells in the chick embryo. Developmental Biology, 10 : 154-190. 1964.

Moné MJ, Volker M, Nikaido O, Mullenders LHF, van Zeeland AA, Verschure PJ, Manders EMM and van Driel R. Local UV-induced DNA damage in cell nuclei results in local transcription inhibition. EMBO, $2: 1013-1017.2001$.

Mori T, Nakane M, Hattori T, Matsunaga T, Ihara M and Nikaido O. Simultaneous establishment of monoclonal antibodies specific for either cyclobutane pyrimidine dimer or (6-4) photoproduct from the same mouse immunized with ultraviolet-irradiated DNA. Photochemistry and Photobiology, $54: 225-232.1991$.

Naito M, Tajima A, Yasuda Y and Kuwana T. Production of germline chimeric chickens, with high transmission rate of donor-derived gametes, produced by transfer of primordial germ cells. Molecular Reproduction and Development, 39:153-161. 1994 a.

Naito M, Tajima A, Tagami T, Yasuda Y and Kuwana T. Preservation of chick primordial germ 
cells in liquid nitrogen and subsequent production of viable offspring. Journal of Reproduction and Fertility, $102: 321-325.1994$ b.

Nakamura A, Amikura R, Mukai M, Kobayashi S and Lasko PF. Requirement for a noncoding RNA in Drosophila polar granules for germ cell establishment. Science, 274 : 2075-2079. 1996.

Nakamura M, Maeda $\mathrm{H}$ and Fujimoto T. Behavior of chick primordial germ cells injected into the blood stream of quail embryos. Okajimas Folia Anatomica Japonica, 67 : 473-477. 1991.

Ono T, Yokoi R and Aoyama H. Transfer of male or female primordial germ cells of quail into chick embryonic gonads. Experimental Animals 45 : 347-352. 1996.

Radman M. Target size of DNA in ultraviolet irradiation. Nature New Biology, 230 : 277-278. 1971.

Reynaud MG. Germ cell population of chick embryos incubated $51 / 2$ days after ultraviolet irradiation of young blastoderms. Comptes Rendus Hebdomadaires des Seances de l'Academie des Sciences. Ser. D, Sciences Naturelles, 284 : 843-846. 1977.

Rupp WD and Howard-Flanders P. Discontinuities in the DNA synthesized in an excisiondefective strain of Escherichia coli following ultraviolet irradiation. Journal of Molecular Biology, 3 : 291-304. 1968.

Sastre MP, Vernet M and Steinert S. Single-cell gel/comet assay applied to the analysis of UV radiation-induced DNA damage in Rhodomonas sp. (Cryptophyta). Photochemistry and Photobiology, $74: 55-60.2001$.

Setlow RB and Carrier WL. Pyrimidine dimers in ultraviolet-irradiated DNA's. Journal of Molecular Biology, 17 : 237-254. 1966.

Singh NP, McCoy MT, Tice RR and Schneider EL. A simple technique for quantitation of low levels of DNA damage in individual cells. Experimental Cell Research, 175 : 184-191. 1988.

Tajima A, Naito M, Yasuda Y and Kuwana T. Production of germ line chimera by transfer of primordial germ cells in the domestic chicken (Gallus domesticus). Theriogenology, 40 : 509-519. 1993.

Tajima A, Naito M, Yasuda Y and Kuwana T. Production of germline chimeras by transfer of cryopreserved gonadal primordial germ cells (gPGCs) in chicken. Journal of Experimental Zoology, $280: 265-267.1998$.

Tajima A, Barbato GF, Kuwana T and Hammerstedt RH. Conservation of a genetically selected broiler line $(42 \mathrm{~L})$ using cryopreserved circulating primordial germ cells (PGCs) isolated by filtration method. Journal of Poultry Science, $40: 53-61.2003$.

Tsunekawa N, Naito M, Sakai Y, Nishida T and Noce T. Isolation of chicken vasa homolog gene and tracing the origin of primordial germ cells. Development, $127: 2741-2750.2000$.

Van Hoffen A, Venema J, Meschini R, van Zeeland AA and Mullenders LHF. Transcriptioncoupled repair removes both cyclobutane pyrimidine dimers and 6-4 photoproducts with equal efficiency and in a sequential way from transcribed DNA xeroderma pigmentosum group C fibroblasts. EMBO Journal, $14:$ 360-367. 1995.

Van Hoffen A, Kalle WHJ, De Jong-Versteeg A, Lehmann AR, Van Zeeland AA and Mullenders LHF. Cells from XP-D and XP-D-CS patients exhibit equally inefficient repair of UVinduced damage in transcribed genes but different capacity to recover UV-inhibited transcription. Nucleic Acids Research, 27 : 2898-2904. 1999.

Yasuda Y, Tajima A, Fujimoto T and Kuwana T. A method to obtain avian germ-line chimaeras using isolated primordial germ cells. Journal of Reproduction and Fertility, $96: 521-528$. 1992. 